\title{
The Effects of ACTOR in College Students' Reading Comprehension and Perceptions
}

\section{Research Article}

\section{Victoria M. REY1}

${ }^{1}$ Kean University, College of Education, New Jersey, USA, ORCID: 0000-0002-9087-3432

To cite this article: Rey, V. M. (2020). The Effects of ACTOR in College Students' Reading Comprehension and Perceptions, International Online Journal of Educational Sciences, 12(3), 126-135.

\begin{tabular}{|c|c|}
\hline ARTICLE INFO & ABSTRACT \\
\hline Article History: & $\begin{array}{l}\text { This study investigated the effects of the ACTOR reading method in the college students' reading } \\
\text { comprehension and their perceptions on the use of this method. The researcher developed this }\end{array}$ \\
\hline Received: 22.07.2019 & method to help students better understand what is explicitly stated and implied in informational \\
\hline \multirow{12}{*}{$\begin{array}{l}\text { Available online: } \\
23.07 .2020\end{array}$} & $\begin{array}{l}\text { texts. It includes a sequence of steps such as activating prior knowledge, concentrating and } \\
\text { connecting this knowledge to new information in the text, triggering appropriate strategies to }\end{array}$ \\
\hline & thoroughly understand what is being read, organizing ideas that have been generated from the text, \\
\hline & and responding to what has been read. Cognitive, metacognitive, learning style, and critical thinking \\
\hline & strategies accompany these steps. Eighty-three college freshmen who attended a developmental or \\
\hline & remedial reading course in a public university in the United States in 2017-2018 participated in this \\
\hline & study. They used the ACTOR reading method in 13 weeks. Findings showed a statistically significant \\
\hline & mean difference between the participants' pre and posttest scaled scores on the Accuplacer reading \\
\hline & comprehension test. They found ACTOR to be very helpful or helpful in reading, studying, and \\
\hline & taking tests. \\
\hline & (C) 2020 IOJES. All rights reserved \\
\hline & Keywords: \\
\hline & College reading, reading comprehension, reading method, reading strategies \\
\hline
\end{tabular}

\section{Introduction}

According to the National Center for Education Statistics, millions of first year students who attend postsecondary institutions in the United States every year are academically underprepared (Chen, 2016). They lack the necessary skills in reading, writing, and math to perform at the college level programs. To address this problem, postsecondary institutions require students to attend remedial intervention programs. or sometimes called developmental education courses.

\footnotetext{
${ }^{1}$ Corresponding author's address: Kean University, New Jersey, USA

Telephone:19087374638

Fax:1 908-737-3935

e-mail: vrey@kean.edu

DOI: https://doi.org/10.15345/iojes.2020.03.010
} 
One of the developmental education courses that students take in a public university in New Jersey is Developmental Reading. They are required to take this course based on their scores that they earned in a college placement test and other factors. This course is designed to develop college students' proficiency in vocabulary and reading comprehension skills that are necessary to fully understand written texts in college content courses. Students who attend this course need a method that should guide them to explicitly follow steps and strategies that will help them understand thoroughly what they read.

The researcher developed the ACTOR reading method to help students better understand what they read. In formulating this method, she considered her experience in teaching developmental reading courses for several years, review of different textbooks in teaching these courses, and research relating to reading and learning; This method is designed to help students to understand what is explicitly stated and implied in texts. It includes a sequence of steps involving cognitive, metacognitive, learning style, and critical thinking strategies. The steps in ACTOR include activating prior knowledge, concentrating and connecting this knowledge to new information in the text, triggering appropriate strategies to thoroughly understand what is being read, organizing ideas that have been generated from the text, and responding to what has been read. Following these steps with accompanying strategies enables students to become engaged and focused because they are actively thinking and connecting to the texts before, during, and after reading (Rey, 2017).

A survey of current textbooks in developmental reading indicates the inclusion of techniques to identify word meanings, main idea, supporting details, transitions, paragraph patterns, inference, purpose and tone, fact and opinion and argument. These skills are applied by responding to multiple choice and open- ended questions. Students need to use techniques to improve these reading skills. It is crucial to consider the specific context in which disciplinary literacies are found and valued. However, this perspective is not typically found in developmental reading textbooks, which often emphasize a general reading comprehension approach (Holschuh \& Paulsen, 2013). Simpson, Stahl, Anderson, \& Francis (2004) recommended that students learn the processes that experts use when they read and think about complex ideas that are found in multiple sources with different perspectives. The strategies and steps in the ACTOR method consider a general reading approach as well as specific disciplinary literacy contents and skills.

In teaching developmental reading, it is also important to teach cognitive strategies that will enable students to acquire the reading skills that they need to comprehend and respond to printed materials in different contexts with varying difficulty. Cognitive strategies in reading include the techniques that visual, auditory, kinesthetic, and critical thinkers use before, during and after reading to create meanings. They activate prior knowledge, visualize, think aloud, ask questions, establish a purpose, recite information without repeatedly returning to the printed material, organize ideas, connect prior knowledge to new information and monitor text comprehension (Lei, Rhinehart, Howard, Holly, \& Cho, 2010; Wong, 2015; Rey, 2014; Pressley, 2006; \& Conley, 2008). Failure to use cognitive strategies efficiently is one of the causes of poor comprehension. The ACTOR method provides steps and accompanying cognitive strategies that are designed to help students to understand and respond to printed materials in different contexts.

Flavell (1976) first used the word metacognition. It refers to the "knowledge concerning one's own cognitive process or anything related to it, e.g., the learning-relevant properties of information or data. For example, a learner engages in metacognition if the person recognizes problems in learning and does something to correct the problems to ensure learning. Metacognition is the individual's awareness of monitoring the processes of knowing something or performing a task and to do something to ensure acquisition of the desired goal. Several studies reported the positive effects of using metacognitive strategies on students' reading performance and their perceptions of reading behavior change (Carretti, Caldarola, 
Tencati \& Cesare, 2014; Eker, 2014; Lan, Lo, \& Hsu, 2014; Zepeda, Richey \& Ronevich , 2015; Hong Nam, Leavell, \& Smaher, 2014 \& Habibian, 2015). While several studies showed the benefits of using metacognitive strategies in improving reading comprehension, some research suggested that students were not engaged in using metacognitive activities because "most students were unaware of the metacognitive process," (Fogarty, 1994). Determining when and where one should apply a previously learned skill requires metacognitive and self-regulation abilities (Fox, 2009; Mayer \& Nash-Ditzel, 2010). Many students were unaware of the metacognitive processes that were necessary in learning and critical thinking. Nist (1993) reported that students entering college often relied on only one learning strategy which was rote memorization. Many students who used some types of self-mentoring strategies tended to be ineffective (Van Blerkom, 2007). According to Halpern (1996) and Simpson and Nist (2000), metacognitive strategies could be taught. ACTOR incorporates metacognition strategies that help readers to monitor their comprehension and change strategies if they do not understand what they read.

\section{Problem Statement and Purpose of the Study}

About $30 \%$ of incoming students in a public university in New Jersey attended a development reading course. They were required to take this course because the Accuplacer placement test results and other measures showed that there was a need for them to improve their reading skills. The researcher designed the steps in ACTOR with accompanying strategies to improve college students' reading comprehension skills. The steps in ACTOR include activating prior knowledge, concentrating and connecting this knowledge to new information in the text, triggering appropriate strategies to understand what is being read, organizing in one's mind the ideas that have been generated from the text, and responding to what has been read to show proof of comprehension. Following these steps with accompanying strategies enables students to become engaged and focused readers because they are actively thinking and connecting to the texts before, during, and after reading (Rey, 2017).

ACTOR could guide students to read efficiently and to cope with the reading demands in content courses. Efficient reading is comprehending what is stated, inferring what the text suggests or implies, and forming valid conclusions, arguments, or new information based on stated ideas in the least possible time (Rey, 2017). ACTOR, the reading method that the researcher designed, was intended to help college students to read efficiently. Finding out the effects of using ACTOR in the college students' reading comprehension and their perceptions on the use of this method could be helpful to students who struggle to fully comprehend explicit and implicit information in informational texts and perform tasks relating to these texts in disciplinary courses.

The purpose of this study was to investigate the effects of ACTOR in students' comprehension and their perceptions on the use of this method. Specifically, two research questions were addressed.

1. What was the difference between the students' reading comprehension before and after using ACTOR?

2. What were the students' perceptions on the use of ACTOR?

\section{Methodology}

The researcher used a combination of quantitative and qualitative methods of research. To determine the difference between the students' reading comprehension before and after using ACTOR, she analyzed the students pre and posttest mean scaled scores in the Accuplacer Reading Comprehension Test through a t-test. Students responded to a questionnaire on their perceptions of using ACTOR in reading comprehension. They also stated their reasons for their answers. 


\section{Participants}

All newly admitted undergraduate students in a public university in the United States were required to take a placement test in reading unless they were exempt from all or part of this testing due to their SAT scores or course work completed at other colleges in 2017-2018. The Accuplacer Reading Comprehension online test was composed of 20 questions. It measured the ability to understand what is read, to identify main ideas, to make inferences and to distinguish between direct statements and secondary or supporting ideas (http://accuplacer.collegeboard.org). Students who did not meet a certain score and other requirements attended a developmental reading course. The researcher invited students who attended a developmental reading course in fall and another set of students who took this course in spring to participate in the study. Eighty students attended the fall semester while 58 attended the spring semester. Although 83 of the 138 students agreed to participate in the study, she demonstrated the steps in ACTOR to all of the students. She used the book, ACTOR: Key to Efficient Reading. This book featured the steps in ACTOR in developing skills that students needed to read closely and critically different types of materials. The reading skills included the following:

1. Connect ideas in sentences through transitional words.

2. Sense a smooth flow of ideas between sentences.

3. Identify the main idea of a paragraph.

4. Identify details that support the main idea of a paragraph.

5. Connect ideas between paragraphs in an article

6. Identify the main thesis of an article.

7. Identify the details that support the main thesis of an article.

8. Recognize paragraph patterns or structures.

9. Make an outline of what is read.

10. Summarize what is read.

11. Distinguish a fact from an opinion.

12. Make an inference.

13. Identify the purpose of an article.

14. Recognize the tone of an article.

15. Identify an argument.

16. Identify the point and supports in an argument.

To develop the aforementioned-skills among the students, the researcher demonstrated the following strategies that accompanied the steps in ACTOR

1. Have a purpose for reading.

2. Read the title or headings.

3. Think about what the title or headings say.

4. Break apart or chunk down ideas in sentences. 
5. Ask, what or who is being talked about in the sentence?

6. Ask, what is being said about who or what in the sentence?

7. Imagine or make a picture in mind of what is being read.

8. Say in own words what the sentence says.

9. Connect ideas in and between sentences.

10. Connect ideas in and between paragraphs.

11.. Ask questions while reading.

12. Know if what is read is understood. Change strategies if needed.

13. Organize ideas in the mind.

14. Recite or write about what has been read.

The researcher guided the students to use the steps and strategies in the ACTOR method in 13 weeks during the semester to improve their reading skills.

\section{Data Collection and Analysis}

All students in a public university in New Jersey took the Accuplacer Reading Comprehension test to determine who should attend a developmental reading course. The researcher demonstrated to students who attended this course in the fall and another set of students who attended the spring term on how to use ACTOR. All students took the Accuplacer posttest. The researcher analyzed the difference between the pre and posttest scaled scores of 83 participants who agreed to participate in the study through SPSS. The t-test was used to identify any statistical difference between the pre and posttest mean scaled scores. Students responded to a question about the effect of using ACTOR by choosing very helpful, helpful, not helpful or no response. They also gave the reasons for their choices. The researcher and two raters tabulated the responses and grouped those that showed similar reasons.

\section{Findings and Discussions}

\section{College Students' Reading Comprehension}

The participants in this study took the Accuplacer Reading Comprehension test at the beginning of the semester to determine the level of their reading comprehension. They also took this test toward the end of the term to determine the effect of using the ACTOR method. The Accuplacer test measured similar comprehension skills but differed in context or content materials during these 2 periods. The researcher used the paired sample t-test to determine the statistical difference between the the mean scaled scores. Table 1 shows that the mean scaled score at the begining of the semester was 62.43. The mean scaled score towards the end of the term was 72.72. The students' average test scaled score on the posttest $(M=72.72, S D=14.87)$ was higher than the mean scaled score on the pretest $(M=62.43, S D=6.82$ and $p=.000)$. There was a statistically significant difference between the pre and posttest mean scaled scores.

Table 1. Reading Comprehension Pretest and Posttest Scaled Sores

\begin{tabular}{lcccc}
\hline Pair 1 & Mean & n & Std. Deviation & Std. Error Mean \\
\hline Pretest & 62,43 & 83 & 6,822 &, 749 \\
\hline Posttest & 72,72 & 83 & 14,847 & 1,630 \\
\hline
\end{tabular}




\section{Students' Perceptions on the ACTOR Method}

The students used the steps and accompanying strategies in the ACTOR method in reading. Table 2 shows that $43 \%$ of the participants found ACTOR to be helpful in reading comprehension while $52 \%$ found it to be helpful. Two students found ACTOR not helpful. Likewise, 2 students did not give any response on the impact of ACTOR in reading comprehension. This means that majority of the participants had a favorable perception of the ACTOR method in comprehending what they read.

Table 2. Students' Perceptions of ACTOR

\begin{tabular}{lll}
\hline Response & No & \% \\
\hline Very Helpful & 36 & 43 \\
\hline Helpful & 43 & 52 \\
\hline Not Helpful & 2 & 2,5 \\
\hline No Response & 2 & 2,5 \\
\hline Total & 83 & 100 \\
\hline
\end{tabular}

Students who found ACTOR to be very helpful cited the following reasons.

1. ACTOR helped me to focus and comprehend better. Now when I read texts, I can honestly say that I understand the author.

2. The ACTOR method helps me break down the work I'm doing. It helps me concentrate faster and makes it easier to understand the text. It also improved my abilities to connect and noticed the tone of the text.

3. The ACTOR method is very helpful because it helps break down what I am reading. I was already good of activating prior knowledge and connecting it to new information, but this helps me to use the different strategies we learned and to organize and respond to new information.

4. The ACTOR method helped me understand what I was reading and kept me from normally drifting away from when I normally don't get what I'm reading.

5. I feel as though the ACTOR method overall, gave a way to better understanding a lot of whatever I read, which did cause me to score higher than usual on tests or quizzes for any class.

6. The ACTOR method was very helpful because it made me break down every sentence before I continued, and as a result, I understood what I was reading more easily. It is normal for this point of view (ACTOR) method to help because it is common sense to think this way while reading. This should be used in elementary schools to help younger kids.

7. The ACTOR method has significantly improved my reading skills because when reading, I follow these steps. My mind processes information more carefully. I am also able to trigger strategies such as visualization, auditory, and kinesthetic. Overall, I feel like I have improved a lot in reading skills.

Students who found ACTOR to be helpful indicated the following reasons.

1. It helped me understand and take my time by analyzing the material and receiving knowledge from it. It helped me break down and understand/comprehend my work.

2. I find the ACTOR method helpful in understanding what I am reading because it helps me to better comprehend the meaning of the text. It makes me take time to think about what I read and what I get out of it.

3. It helps me organize ideas. It helps me elaborate what I'm reading, so I can fully comprehend.

4. As I read a passage, I look to think if I have any prior knowledge, as well as create images in my head and break down each supporting detail.

5. The ACTOR method is helpful because it allowed me to connect ideas and new information with the passages.

It also helps me better identify main ideas as well as minor and major details when I'm reading something.

6. I never used it before, but now it is starting to help me understand what I am reading. 
7. ACTOR is helpful because I take my time to stop and try to process what I'm reading.

8. It was helpful because when I applied what I learned in the work and quizzes, I received good grades

Students who found ACTOR not to be very helpful stated the following reasons.

1. If I activate prior knowledge, I start getting sidetracked. If I stop and ask myself questions after each sentence, I lose focus.

2. I feel like the ACTOR method is too long. If I read something I'm not going to want to go through this whole process just depict a paragraph about something I will forget about it the very next day.

\section{Conclusions and Recommendations}

The researcher designed the ACTOR method to help college students better understand what they read. ACTOR includes steps and accompanying strategies to develop the reading skills that prepare students to be college and career ready. These reading skills are based on the Common Core Standards (Common Core State Standards Initiative, 2010). The steps in ACTOR include activating prior knowledge, concentrating and connecting this knowledge to new information in the text, triggering appropriate strategies to understand what is being read, organizing in one's mind the ideas that have been generated from the text, and responding to what has been read to show proof of comprehension. The researcher demonstrated to college students how to use the ACTOR method in improving reading skills. After using ACTOR, the participants in the study showed an improvement in their reading comprehension based on their scores in the Accuplacer test. There was a statistically significant difference between the pre and posttest mean scaled scores. It appears that the students benefited from using the steps and accompanying strategies in the ACTOR method. Some studies show that the use of strategies to guide students to improve their reading performance were helpful. The teachers' emphasis on three dimensions of instruction such as pedagogical structure, teacher-directed instruction, and support for students contributed to students' reading comprehension (Carlisle, Kelcey, Berebitsky \& Phelps, 2011). The Fayetieville State University's Reading Across the Curriculum where faculty applied effective strategies to integrate reading comprehension into their courses resulted in significant improvement in students' performance outcomes (Anderson, T. \& Kim, J; 2011). The Moodle-supported strategy instruction on both reading comprehension and strategy use among EFL (English as a Foreign Language) had helped in improving students' reading comprehension performance (Tsai. Yea-Ru \& Talley, P., 2014).

Students who used ACTOR in the developmental reading course for a semester have generally found this method very helpful or helpful in understanding different types of reading materials and taking tests. Their favorable responses toward using ACTOR may have also affected their reading comprehension. They cited several reasons for their positive responses. Kırmızı (2011) conducted a study to determine the relationship between levels of reading comprehension strategy use, reading attitudes, and the amount of reading per year. It yielded a positive significant relationship between the level of reading comprehension strategy use and attitudes toward reading among elementary school students. In an analysis of 32 studies regarding students' attitudes toward reading and achievement in reading, results suggested that the relationship between attitudes and achievement in reading was generally of moderate strength although strong among elementary grade students (Petscher, 2010). Students showed an improvement in their reading comprehension and they perceived an improvement in their reading skills after applying strategies for improving reading comprehension, (Rey, V., Kastner, J., Young, E. \& Schuman, D., 2013).

The participants in this study were college students who attended a developmental reading course in a public university in the United States of America. The researcher developed and used the ACTOR method to help college students to improve their reading comprehension skills. To find out the benefits of using this 
method, students took the Accuplacer test on reading comprehension and responded to a questionnaire in the beginning and toward the end of the semester. With these limitations, other studies may be conducted that involve different methods, instruments and students in different academic settings to validate or further determine the benefits of the ACTOR reading method in improving students' reading comprehension and attitude.

\section{Acknowledgements}

The author acknowledges the Kean University Foundation, Diana Espinal, and Dr. Ethel Young for their support in completing this research. 


\section{REFERENCES}

Acculacer test. (2012). Retrieved from: http://accuplacer.collegeboard.org.

Anderson, T. \& Kim, J. (2011). Strengthening college students' success through the rac. Journal of College Reading \& Learning, 42(1) 61-78.

Carlisle, J; Kelcey, B; Berebitsky, D; \& Phelps, G. (2011). Embracing the complexity of instruction: A study of the effects of teachers' instruction on students' reading comprehension, Scientific Studies of Reading, 15:5, 409-439, DOI: 10.1080/10888438.2010.497521

Carretti, B., Caldarola, N., Tencati, C. \& Cornoldi C. (2014). Improving reading comprehension in reading and listening settings: The effect of two training programs focusing on metacognition and working memory. British Journal of Educational Psychology, 84, 194-210.

Chen, X. (2016). Remedial course taking at U.S. public 2- and 4-year institutions: scope, experiences, and outcomes (NCES 2016-405). U.S. Department of Education. Washington, DC.

Conley, M. (2008). "Cognitive strategy instruction for adolescents: What we know about the promise, what we don't know about the potential." Harvard Educational Review, 78(1), 84-206.

Common Core State Standards Initiative. (2010) Common core state standards for English language arts and literacy. Washington, D.C: National Governors Association Center for Best Practices \& Council of Chief State School Officers

Eker1, C. (2014). The effect of teaching practice conducted by using metacognition strategies on students' reading comprehension skills. International Online Journal of Educational Sciences, 6(2), 269-280.

Flavell, J. H. (1976). Metacognitive aspects of problem solving. In L.B. Resnick (Eds.). The nature of intelligence (pp. 231-245). Mahwah, NJ: Lawrence Erlbaum.

Fox, E. (2009). The role of reader characteristics $n$ processing and learning from informational text. Review of Educational Research, 79 (1), 197-261.

Fogarty, R. (1994). How to teach for metacognition. Palatine, IL: IRI/Skylight.

Goetz, \& P. A. Alexander (Eds.), learning and study strategies: Issues in assessment, instruction, and evaluation (pp. 3 - 9). New York: Academic Press.

Habibian, H. (2015). The impact of training metacognitive strategies on reading comprehension among ESL learners. Journal of Education and Practice, 6(28), 61-69.

Halpern, D. F. (1996). Thought and knowledge: An introduction to critical thinking. Mahwah, NJ: Erlbaum Associates.

Holschuh, J.P. \& Paulson, E.J. (2013). The terrain of college developmental reading. Retrieved from https://www.crla.net/docs/TheTerrainofCollege91913.pdf

Hong-Nam, K., Leavell, A., \& Smaher, S. (2014). The relationships among reported strategy, metacognitive awareness and reading achievement of high school students. Reading Psychology, 35, 762-790. doi: 10.1080/02702711.2013.807900.

Lan, Y., Lo, Y. \& Hsu, Y. (2014). The effects of meta-cognitive instruction on students' reading comprehension in computerized reading contexts: A Quantitative meta-analysis. Educational Technology \& Society, 17(4), 186-202.

Lei, S. A., Rhinehart, P. J., Howard, H. A., \& Cho, J. K. (2010). Strategies for improving reading comprehension among college students. Reading Improvement, 47(1), 30-42.

Mayer, R. E., \& Wittrock, M. C. (1996). Problem-solving transfer. In D.C. Berliner \& R. C. Calfee (Eds.), Handbook of Educational Psychology (pp. 47-62). New York, NY: Macmillan.

Nash-Ditzel, S. (2010). Metacognitive reading strategies can improve self-regulation. Journal of College Reading and Learning, 40(2), 45-63.

Nist, S. (1993). What the literature says about the academic literacy. Georgia Journal of Reading, 11-18. 
Petscher, Y. (2010). A meta-analysis of the relationship between student attitudes towards reading and achievement in reading. Journal of Research in Reading, 33(4), 335-355.

Pressley, M. (2006). Reading Instruction that Works: The Case for Balanced Teaching. New York, NY: Guilford.

Rey, V. (2014). Enhancing reading proficiency through reader response. Paper presented the College Reading and Learning Association Northeast Chapter Conference Weston, MA.

Rey, V. (2017). ACTOR: Key to efficient reading. Dubuque, IA: Kendall Hunt.

Rey, V., Kastner, J., Young, E. \& Schuman, D. (2013). The college students' perceptions of their reading skills and knowledge. Care for Affect in Reading Education Journal. 28, 37-44.

Simpson, M., Stahl, N., \& Anderson Francis, M. (2004). Reading and learning strategies: Recommendations for the 21st Century. Journal of Developmental Education (28) 2, 1-13.

Simpson, M. L., \& Nist, S. L. (2000). An update on strategic learning: It's more than textbook reading strategies. Journal of Adolescent \& Adult Literacy, 43 (6), 528-541.

Tsai. Yea-Ru \& Talley, P. (2014) The effect of a course management system (CMS)-supported strategy instruction on EFL reading comprehension and strategy use. Computer Assisted Language Learning, 27 (5), 422-438.

Van Blerkom, M. \& Van Blerkom, D. (2007). Self-Monitoring strategies used by developmental and nondevelopmental college students. Best Practices in College Reading and Learning, 107-123

Wong, Linda. (2015). Essential study skills, (8th ed.). Stamford, Connecticut: Cengage Learning.

Zepeda, C., Richey, E., Ronevich, P. \& Nokes-Malach, T. (2015). Direct instruction of metacognition benefits, adolescent science learning transfer and motivation: An in vivo study. Journal of Educational Psychology, 107(4), 954-970. 